\title{
The Role of Tumoral FOXP3 on Cell Proliferation, Migration, and Invasion in Gastric Cancer
}

\author{
Lu Zhang Jianghao Xu Xuan Zhang Yi Zhang Lu Wang Xiaoxu Huang \\ Zekuan Xu
}

Department of General Surgery, the First Affiliated Hospital of Nanjing Medical University, Jiangsu, PR China

\section{Key Words}

FOXP3 • Gastric cancer • Proliferation • Migration • Invasion

\begin{abstract}
Background/Aims: There is little published data on the role of FOXP3 in gastric cancer. Methods: FOXP3 expression and localization in gastric cancer tissues and cells were examined by immunohistochemistry, RT-PCR, flow cytometry, western blot, and laser confocal microscopy. CCK8, plate clone, wound healing, and transwell insert assays were performed for gastric cancer cells. Potential molecules and signaling pathways were screened using highthroughput transcriptome sequencing. Results: FOXP3 expression in gastric cancer tissues was higher than that in para-carcinoma tissues. It was restricted to the cytoplasm of paracarcinoma tissues, but was observed in the cytoplasm or/and nuclei of gastric cancer tissues. FOXP3 expression was positively correlated with pathological grading, and was detected in gastric cancer and GES-1 cells, where it was expressed in the cytoplasm alone, or in both the cytoplasm and the nucleus. FOXP3 overexpression promoted cell proliferation, migration, and invasion, while FOXP3 knockdown suppressed these effects. Furthermore, RT-PCR and ELISA confirmed that FOXP3 upregulation resulted in increased TGF- $\beta$ expression and secretion in gastric cancer cells. Conclusion: FOXP3 expression was associated with degree of gastric cancer differentiation. In addition, upregulated and ectopic tumoral FOXP3 can promote gastric cancer proliferation, migration, and invasion, partly through the TGF- $\beta$ pathway.
\end{abstract}

(C) 2017 The Author(s)

Published by S. Karger AG, Basel

\section{Introduction}

Gastric cancer (GC) is the fourth most common malignant disease and the third leading cause of cancer-related deaths worldwide [1,2]. Almost $50 \%$ of gastric cancer patients are Chinese, many of whom are diagnosed with advanced stage cancer [3]. Over the past few decades, many patients have died from cancer metastasis and recurrence despite 
comprehensive treatment strategies including surgery, postoperative chemotherapy, adjuvant chemotherapy, and radiotherapy [4].

Forkhead box protein 3 (FOXP3) is a member of the forkhead/winged helix family of transcription factors, and mutation in this gene is responsible for X-linked autoimmune diseases in both mice (scurfy mice) and humans (immune dysregulation, polyendopathy, enterophathy, X-linked, IPEX) [5-7]. Until a few years ago, FOXP3 expression was thought to be restricted to lymphocytes. Research in immune cells indicated that FOXP3 is essential for the development and function of $\mathrm{CD}^{+}{ }^{+} \mathrm{CD} 25^{+}$regulatory T cells [8-11]. However, FOXP3 has also been found to be expressed in epithelial cells of human tissues under both normal conditions and during aggressive cancers, including breast [12-14], ovarian [15], lung [16], and prostate cancers [17]. In cancer tissues, FOXP3 can either be overexpressed or reduced at both transcriptional and translational levels $[12,15,17]$. It is becoming clear that FOXP3 plays an important role in controlling the expression of numerous genes involved in cancer development in the epithelium [17-20]. However, the effects of FOXP3 on cancer are very controversial, such as its roles in breast, ovarian, esophageal, and cervical cancer $[13,15,17$, 21-24]. Zhang and Sun demonstrated that FOXP3 is able to significantly reduce the migration and invasion capability of malignant ovarian cells [15]. Another study indicated that FOXP3 expression in pancreatic cancer cells allows tumor cells to evade the immune system, thus promoting tumor growth [25]. However, the mechanisms underlying these inconsistent results remain largely unknown.

The function of FOXP3 in gastric cancer is also controversial, and the underlying mechanism behind its effects is not fully understood. Some studies showed that FOXP3 can inhibit cell proliferation and induce apoptosis of gastric cancer cells [26], and that high FOXP3 expression is a predictor of survival $[27,28]$. Hao et al. showed that FOXP3 acts as a tumor suppressor in gastric cancer $[29,30]$. On the other hand, Wang et al. demonstrated that elevated FOXP3 expression is associated with increased lymph node metastasis [31]. Yoshii et al. also showed that FOXP3 expression is associated with lymph node metastasis in signet ring cell carcinoma of the stomach [32]. In addition, the study by Guo on Wistar rats indicated that FOXP3 may be important for gastric cancer development [33].

In this study, we examined the expression and localization of FOXP3 in both GC cells and GC tissues, and investigated the association between FOXP3 expression and clinicopathological features of cancer, as well as its effects on malignant behaviors of GC cell lines. We observed abnormal and ectopic FOXP3 expression in gastric cancer. FOXP3 was correlated with degree of GC differentiation, and upregulated FOXP3 promoted cell proliferation, migration, and invasion in GC. Furthermore, RNA-sequencing results indicated that several potential molecules and signaling pathways may be involved in the process, including the TGF- $\beta$ pathway. RT-PCR and ELISA confirmed that FOXP3 upregulation increases the expression and secretion of TGF- $\beta$ in GC cells.

\section{Materials and Methods}

Tissue specimens and cell lines

In this study, GC and para-carcinoma tissues were freshly prepared, and were gifted to us by the Outdo Biotech (Shanghai, CN). Human GC cell lines MGC803, BGC823, SGC7901, MKN45, AGS, HGC27, and normal human gastric epithelial cell line (GES-1) were purchased from Cell Center of Shanghai Institutes for Biological Sciences (Shanghai, CN). Cells were cultured in RPMI-1640 medium (Gibico, USA), supplemented with $10 \%$ fetal bovine serum (FBS) (Hyclone, USA) and 1\% penicillin/streptomycin (Gibico, USA) at $37^{\circ} \mathrm{C}$ and $5 \% \mathrm{CO}_{2}$ in a humidified incubator.

Immunohistochemistry

Immunohistochemistry was performed as previously described [34]. Briefly, paraffin-embedded sections were de-waxed in xylene, and were rehydrated in graded alcohols. Heat-activated antigen retrieval was then performed with sodium citrate buffer $(10 \mathrm{mM}, \mathrm{pH} 6.0)$. Tissue sections were heated via 
the microwave method for 20 min. Endogenous peroxidase activity was suppressed by exposure to $3 \%$ hydrogen peroxide for $10 \mathrm{~min}$. Slides were then blocked with 5\% BSA (Boster Bioengineering, Wuhan, CN), and were incubated with diluted (1:100) primary FOXP3 antibody (236A/E7, Abcam, USA) for $1 \mathrm{~h}$ at $37^{\circ} \mathrm{C}$. This was followed by $20 \mathrm{~min}$ incubation with diluted secondary antibody (1:2000) (Abcam, USA) at $37^{\circ} \mathrm{C}$. Slides were visualized with DAB, and were counterstained with hematoxylin for microscopic examination. Staining intensity was given a score between 1 and 3 (1: no staining or light brown staining; 2: weak to moderate brown staining; 3: moderate to intense brown staining). The percentage of positive cells was calculated from 10 randomly selected fields. Both staining intensity and percentage of positive staining were used to evaluate protein expression. Cases with $\geq 10 \%$ positive cells, in addition to achieving a score $\geq$ 2 were considered to be positive.

\section{Real-time polymerase chain reaction (RT-PCR)}

Total RNA was extracted from cells using the Trizol reagent (Applied Science, Germany) according to manufacturer's instructions. Purity and concentration of extracted RNA were assessed by NanoDrop ND2000 (NanoDrop Technologies, USA). cDNA was then synthesized using the PrimeScript RT Reagent Kit (Takara, JPN) according to the manufacturer's instructions. Real-time PCR was performed on the Applied Biosystems 7500 Real-Time PCR System (ABI, USA) with SYBR Premix Ex Taq (Takara, JPN). Final reaction volume was $20 \mu \mathrm{L}$, and included $2 \mu \mathrm{L}$ cDNA, $10 \mu \mathrm{L}$ SYBR Green Master Mix, $0.5 \mu \mathrm{L}$ each of the forward and reverse primers $(10 \mathrm{pmol})$, and $7 \mu \mathrm{L}$ nuclease-free water. Melting curve analysis was performed to validate each PCR product. Relative expression level of target mRNAs were normalized to that of the endogenous control ( $\beta$-actin), and was calculated based on the $2^{-\Delta \Delta \mathrm{Ct}}$ comparative method, where $\Delta \mathrm{CT}=\left(\mathrm{CT}_{\mathrm{Foxp} 3}-\mathrm{CT}_{\beta \text {-actin }}\right)$, and $2^{-\triangle \Delta C T}=2^{\mathbb{Q}(\triangle C \text { Tobservation group- } \triangle \mathrm{CT} \text { control group) }}$. PCR for each sample was performed in triplicates. All primers used are listed in Table 1.

Flow cytometry

A total of $5 \times 10^{5}$ cells were harvested and washed with PBS. Cells were then resuspended in $1 \mathrm{~mL}$ FOXP3 Fixation/Permeabilization working solution (eBioscience, USA), and were incubated for $60 \mathrm{~min}$ at RT. Flow Cytometry Staining Buffer ( $2 \mathrm{~mL}$, eBioscience, USA) was added to each tube, and cells were centrifuged at 300-400 $\mathrm{g}$ for $5 \mathrm{~min}$ at RT. The supernatant was discarded, and cell pellets were resuspended in $100 \mu \mathrm{L}$ Flow Cytometry Staining Buffer. APC-conjugated anti-FOXP3 antibody (5 $\mu \mathrm{L}$, eBioscience, USA) was added to detect intracellular antigen via flow cytometry.

\section{Western blot}

Cells were collected and lysed in $400 \mu \mathrm{L}$ cold radioimmunoprecipitation assay buffer containing freshly added $0.01 \%$ protease inhibitor. Total protein was extracted from cell homogenates according to manufacturer's instructions. Protein concentration was determined by BCA. Approximately $25 \mu \mathrm{g}$ extracted protein in each group was denatured for $10 \mathrm{~min}$ at $95^{\circ} \mathrm{C}$. Proteins were run on $10 \%$ SDS-PAGE, and were transferred onto PVDF membranes ( $100 \mathrm{~V}, 60 \mathrm{~min}$ ). Membranes were blocked with 5\% non-fat milk at room temperature (RT) for $1 \mathrm{~h}$, and were incubated in FOXP3 mouse monoclonal antibody (236A/E7, Abcam, USA) at a dilution of 1:200 at $4^{\circ} \mathrm{C}$ overnight. After the final wash, membranes were incubated with horseradish peroxidase-conjugated secondary IgG antibody (Santa, USA) at 1:2000 dilution for $1 \mathrm{~h}$ at $37^{\circ} \mathrm{C}$. Membranes were developed using the Enhanced Chemiluminescence Detection Kit.

Table 1. Primer sequences used in this stud

\begin{tabular}{lll}
\hline Gene & Primer (forward) & Primer (reverse) \\
\hline Foxp3 & 5'-TACTTCAAGTTCCACAACATGCGACC-3' & 5'-CGCACAAAGCACTTGTGCAGACTCAG-3' \\
TGF- $\beta 1$ & 5'-CTAATGGTGGAAACCCACAACG-3' & 5'-TATCGCCAGGAATTGTTGCTG-3' \\
$\beta$-actin & 5'-CATGTACGTTGCTATCCAGGC-3' & 5'-CTCCTTAATGTCACGCACGAT-3' \\
\hline
\end{tabular}


Enzyme linked immunosorbent assay (ELISA)

Cells $\left(2 \times 10^{6}\right)$ were seeded in 6-cm culture dishes, and were cultured in RPMI-1640 supplemented with 5\% FBS. Media were replaced with serum-free RPMI- 1640 when cells reached $80 \%$ confluence. Cell supernatant was harvested after a 72-h culture. The level of TGF- $\beta 1$ in the supernatant was detected using the human TGF- $\beta 1$ ELISA kit (Multisciences, Hangzhou, CN) according to manufacturer's instructions. Briefly, serially diluted standards and samples (stepwise 1:2 dilution) were added into the wells $(100 \mu \mathrm{L} /$ well), and were incubated at RT for $2 \mathrm{~h}$. Cells were washed three times with the washing buffer. HRP-conjugated secondary antibody at a dilution of 1:1000 $(100 \mu \mathrm{L} /$ well $)$ was added to the cells, which were incubated at RT for $1 \mathrm{~h}$. The plate was washed three times, and cells were then incubated with DAB solution for 10-20

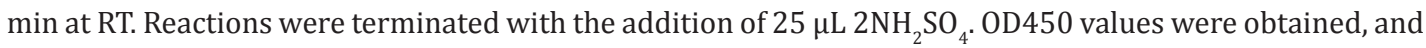
concentration of TGF- $\beta 1$ was extrapolated from the standard curve.

FOXP3 localization by laser confocal microscopy

Cells $\left(1 \times 10^{5} /\right.$ well $)$ were grown on glass slides in 6-well plates in triplicates. After $48 \mathrm{~h}$, cells were washed and fixed in $2 \%$ paraformaldehyde $(1 \mathrm{~mL} /$ well) for $10 \mathrm{~min}$ at RT. Cells were then washed and blocked with blocking buffer ( $1 \mathrm{~mL} /$ well) for $60 \mathrm{~min}$ at RT. Anti-FOXP3 antibody (236A/E7, Abcam, USA) $(1: 100,1 \mathrm{~mL})$ was added into each well, and the plates were incubated at $4^{\circ} \mathrm{C}$ overnight. FITC-conjugated secondary IgG antibody (eBioscience, USA) $(1: 500,1 \mathrm{~mL})$ was added to the cells, which were incubated for $30 \mathrm{~min}$ at RT. After the final wash, DAPI staining buffer was added. Cells were washed after a $10 \mathrm{~s}$ staining period at RT. The expression and localization of FOXP3 were visualized by laser confocal microscopy (LSM5, Carl Zeiss, Germany).

\section{FOXP3 knockdown by transient RNA interference}

HGC27 cells $\left(1.5 \times 10^{5}\right)$ were seeded into 6-well plates, and were incubated for $24 \mathrm{~h}$. Cells were transiently transfected with three synthesized FOXP3 siRNAs (designated as siRNA-1259, siRNA-1355, and siRNA-1896), or the negative control (NC) (Genpharma, Shanghai, China) using Lipofectamine 2000 (Invitrogen). Media were changed (RPMI-1640 with 10\% FBS) 4-6 h later. Cells were harvested $48 \mathrm{~h}$ after transfection, and RT-qPCR and flow cytometry were performed. The most efficient siRNA was chosen for further experiments. The sequences of FOXP3 siRNAs used are listed in Table 2.

\section{Establishment of stable FOXP3-overexpressing cell line}

SGC7901 cells $\left(1.5 \times 10^{5}\right)$ were seeded into six-well plates and incubated for $24 \mathrm{~h}$. Cells were transfected with FOXP3-expressing lentivirus or pEX-3 lentivirus vector as a negative control (Genpharma, Shanghai, China) using Lipofectamine 2000 (Invitrogen). Media (RPMI-1640 with 10\% FBS) were changed 4-6 h later. After 48 h, G418 (Sigma, USA) was added into the wells at a final concentration of $100 \mu \mathrm{g} / \mathrm{mL}$, and media were changed every 2-3 days. After 10-14 days, stable FOXP3-expressing cell lines were established, which were verified using RT-qPCR, flow cytometry, and laser confocal microscopy.

\section{CCK8 assay}

Cells ( $5 \times 10^{3} /$ well) were seeded into 96-well plates in triplicates, and were cultured in $100 \mu \mathrm{L} \mathrm{RPMI-}$ 1640 containing 10\% FBS for 5 days. The Cell Counting Kit-8 (CCK8) was used to evaluate cell proliferation. Briefly, $10 \mu \mathrm{L}$ CCK8 solution was added to each plate, and cells were incubated for $3 \mathrm{~h}$ at $37^{\circ} \mathrm{C}$. Cell viability was measured at $450 \mathrm{~nm}$.

Plate clone assay

Cells were seeded into 6-well plates with 100 or 500 cells in each well, and were cultured in RPMI-1640 with 10\% FBS. Upon visualizing the colonies after 10-14 days, the plates were washed with PBS and stained with crystal violet for $15 \mathrm{~min}$. All experiments were performed in triplicates.

Table 2. Sequences of FOXP3 siRNA used in this study

\begin{tabular}{ll}
\hline siRNA & \\
\hline siRNA-1259 & 5'- GGACACUCAAUGAGAUCUATT.-3' \\
siRNA1355 & 5'- GUCUGCACAAGUGCUUUGUTT -3' \\
siRNA-1896 & 5'- CUGCCUCAGUACACUCAAATT -3' \\
Negative control (NC) & 5'- UUCUCCGAACGUGUCACGUTT -3' \\
\hline
\end{tabular}




\section{Cellular Physiology Cell Physiol Biochem 2017;42:1739-1754 \begin{tabular}{l|l} 
DOI: 10.1159/000479442 & $\begin{array}{l}\text { O 2017 The Author(s). Published by S. Karger AG, Basel } \\
\text { www.karger.com/cpb }\end{array}$
\end{tabular} Zhang et al.: The Role of Tumoral FOXP3 in Gastric Cancer}

Matrigel invasion assay and cell migration assay

Transwell insert assays were performed to assess the invasive/migratory capacities of the cells. Transwell chambers with PVDF filters (pore size $8.0 \mu \mathrm{m}$ ), were either uncoated (migration assay) or coated (invasion assay) with $50 \mu \mathrm{L}$ Matrigel diluted 1:3 in serum-free RPMI-1640. Cells $\left(10^{5} /\right.$ well) were suspended in $200 \mu \mathrm{L}$ serum-free RPMI-1640, and were seeded into the upper chambers in triplicates. RPMI1640 containing $10 \%$ FBS $(600 \mu \mathrm{L})$ was added to the lower chamber as a chemotactic factor. Following a 24-h incubation period at $37^{\circ} \mathrm{C}$, the non-invading/migrating cells on the upper surface of the filter were carefully removed with a cotton swab. Cells that migrated through the $8-\mu \mathrm{m}$ sized pores and adhered to the lower surface of the filter were fixed with $4 \%$ paraformaldehyde, stained with $0.1 \%$ crystal violet, and were imaged. Cells in five non-overlapped fields were counted under a microscope (Olympus, JPN), and the mean cell counts were calculated.

\section{Wound healing assay}

Cells $\left(3 \times 10^{5} /\right.$ well $)$ were seeded and grown in 6-well plates for $48 \mathrm{~h}$ until full confluence was reached. Wells were then washed with PBS to remove non-adherent cells, and a sterile $1000 \mu \mathrm{L}$ pipette tip was used to make a uniform scratch at the center of the well. After a 24-h incubation period in serumfree RPMI-1640, the horizontal distance between the sides of the wound was measured; experiments were performed in triplicates.

\section{High-throughput RNA-sequencing}

High-throughput RNA-sequencing was conducted (Vazyme Biotech, CN) to screen differentially expressed genes between SGC7901 FOXP3 (FOXP3-overexpressing SGC7901 cells) and SGC7901 control cells (pEX-3 transfected SGC7901 cells).

Statistical analysis

Statistical analysis was performed using the SPSS 21.0 statistical package. Quantitative data are presented as mean $\pm \mathrm{SD}$, and were analyzed by ANOVA or two- tailed Student's $t$-tests. Categorical data were evaluated by the Chi-square test. $P<0.05$ was considered to be statistically significant.

\section{Results}

FOXP3 expression in GC tissues and its association with clinicopathological characteristics

The tissue microarray was comprised of 15 pairs of GC and para-carcinoma tissues, which were collected from 15 gastric adenocarcinoma patients, including 10 men and 5 women. The mean age of the patients at the time of surgery was $60.8 \pm 13.2$ years (ranging from 38-81 years), and the average tumor size was $5.1 \pm 1.7 \mathrm{~cm}$. Based on the post-surgery pathology report, 9 (60\%) samples were categorized as grade II (moderately differentiated), and 6 (40\%) samples were categorized as grade III (poorly differentiated). Based on the international TNM classification system, $9(60.0 \%)$ patients had stage I and $6(40 \%)$ patients

Table 3. Summary of clinicopathological characteristics of 15 GC patients

\begin{tabular}{|c|c|}
\hline Characteristics & \\
\hline Mean age (year) & $60.8 \pm 13.2$ \\
\hline \multicolumn{2}{|l|}{ Age range $(\mathrm{n} / \%)$} \\
\hline$>60$ years & $9 / 60.0$ \\
\hline$\leq 60$ years & $6 / 40.0$ \\
\hline \multicolumn{2}{|l|}{ Gender $(\mathrm{n} / \%)$} \\
\hline Male & $10 / 66.7$ \\
\hline Female & $5 / 33.3$ \\
\hline Tumor size $(\mathrm{cm})$ & $5.1 \pm 1.7$ \\
\hline \multicolumn{2}{|l|}{ Tumor size (n/\%) } \\
\hline$<5.1 \mathrm{~cm}$ & $10 / 66.7$ \\
\hline$\geq 5.1 \mathrm{~cm}$ & $5 / 33.3$ \\
\hline \multicolumn{2}{|c|}{ Lymph node metastasis (n/\%) } \\
\hline Positive & $6 / 40.0$ \\
\hline Negative & $9 / 60.0$ \\
\hline \multicolumn{2}{|c|}{ Pathological grading } \\
\hline II & $9 / 60.0$ \\
\hline III & $5 / 40.0$ \\
\hline \multicolumn{2}{|c|}{ Clinical stage $(\mathrm{n} / \%)$} \\
\hline I & $9 / 60.0$ \\
\hline II & $5 / 40.0$ \\
\hline
\end{tabular}




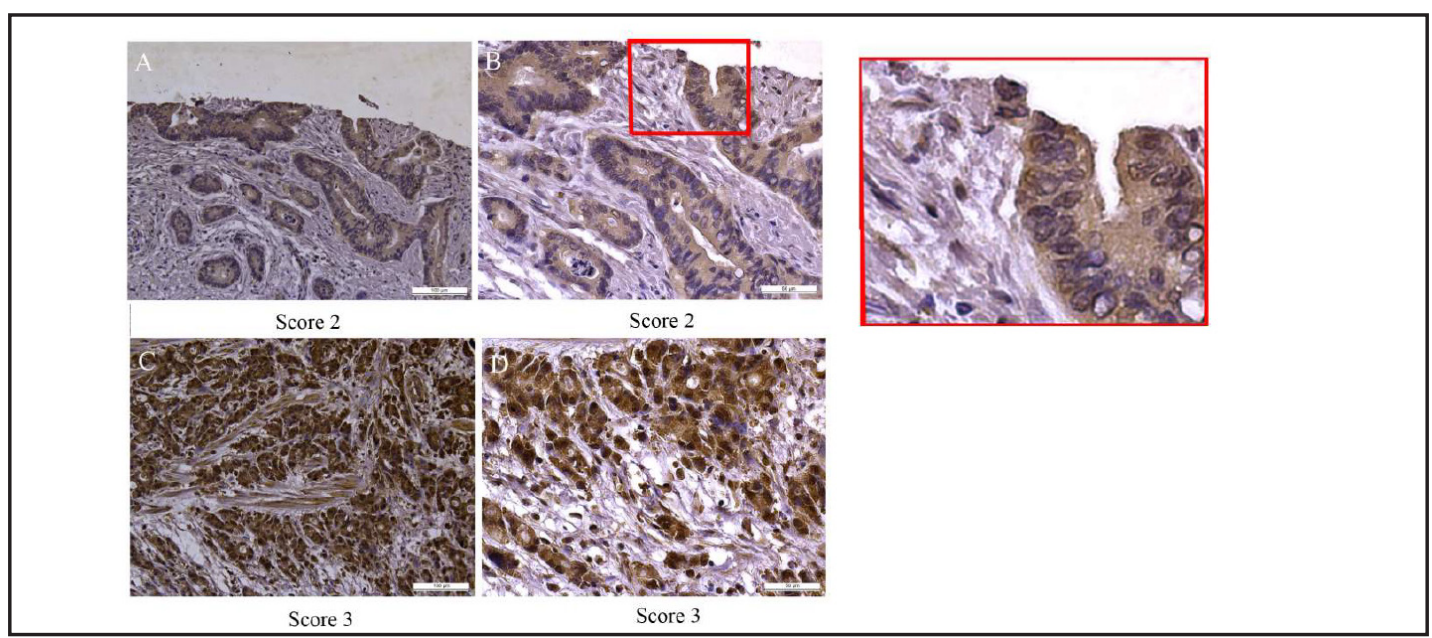

Fig. 1. Expression and localization of FOXP3 in GC tissues. (A) and (B) are representative images of FOXP3 expression with an intensity score of 2. (C) and (D) are representative images of FOXP3 expression with an intensity score of 3. FOXP3 was detected in GC tissues, and were expressed in the cytoplasm in most cases; (A) 200X magnification, (B) 400X magnification. Local enlargement in the rectangular area is shown on the right. In a few GC cases, FOXP3 expression was detected in both the cytoplasm and the nucleus; (C) 200X magnification, (D) 400X magnification.

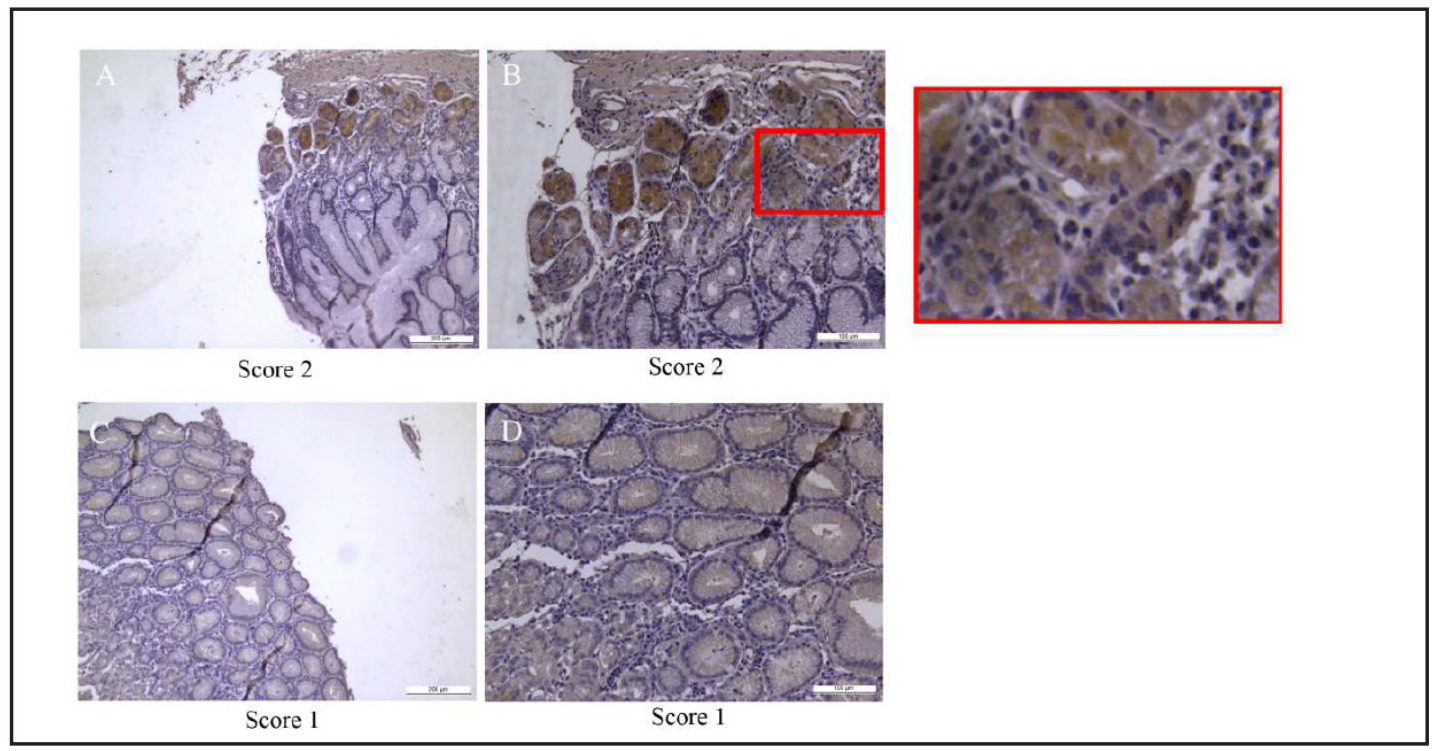

Fig. 2. Expression and localization of FOXP3 in para-carcinoma tissues. (A) and (B) are representative images of FOXP3 expression with an intensity score of 2. (C) and (D) are representative images of FOXP3 expression with an intensity score of 1. FOXP3 was detected in pare-cancerous tissues, and was expressed in the cytoplasm of gastric mucosal cells on the basal side of the mucosal layer; (A) 100X magnification, (B) 200X magnification. Local enlargement in the rectangular area is shown on the right. In pre-cancerous tissues, FOXP3 was not detected on the basal side of the mucosal layer; (C) 100X magnification, (D) 200X magnification.

had stage II cancer. Among all the patients, 6 (40\%) patients had lymph node metastases (Table 3).

Immunohistochemistry results showed that FOXP3 can be detected in both GC and paracarcinoma tissues. In GC tissues, FOXP3 was expressed mostly in the cytoplasm, with only a few cases that exhibited FOXP3 expression in both the cytoplasm and the nucleus (Fig. 1). In para-carcinoma tissues, FOXP3 expression was mostly restricted to the cytoplasm; FOXP3positive cells were centered only on the basal side of the mucosal layer (Fig. 2). Overall, FOXP3 KARGER 
expression in GC tissues was higher than that in para-carcinoma tissues. We categorized GC tissues into a high expression group (higher than median expression level) and a low expression group (lower than median expression level) based on expression levels of FOXP3. As shown in Table 4, there were five (83.3\%) patients in grade III that showed strong FOXP3 expression. On the other hand, only two $(22.2 \%)$ patients in grade II demonstrated high FOXP3 expression. The difference between the two groups was found to be significant $(P=0.041)$, suggesting that expression level of FOXP3 is correlated with degree of GC differentiation. However, no correlations were found between FOXP3 expression and other characteristics, such as lymph node metastases and clinical staging.

\section{FOXP3 expression in GC cells}

We also measured expression levels of FOXP3 in GC and GES-1 cells by RT-qPCR, flow cytometry, and western blot. It was shown that the expressional level of FOXP3 was increased in undifferentiated and poorly differentiated cell lines by comparison
Table 4. The association between FOXP3 expression and clinicopathological characteristics

\begin{tabular}{|c|c|c|c|c|}
\hline \multirow[t]{2}{*}{ Characteristics } & \multicolumn{2}{|c|}{ FOXP3 } & \multirow{2}{*}{ Total } & \multirow{2}{*}{$P$ value } \\
\hline & High & Low & & \\
\hline Total case & 7 & 8 & 15 & \\
\hline Age & & & & 1.000 \\
\hline$>60$ years & 4 & 5 & 9 & \\
\hline$\leq 60$ years & 3 & 3 & 6 & \\
\hline Gender & & & & 0.608 \\
\hline Male & 4 & 6 & 10 & \\
\hline Female & 3 & 2 & 5 & \\
\hline Tumor size (n/\%) & & & & 0.608 \\
\hline$<5.1 \mathrm{~cm}$ & 4 & 6 & 10 & \\
\hline$\geq 5.1 \mathrm{~cm}$ & 3 & 2 & 5 & \\
\hline $\begin{array}{l}\text { Lymph node metastasis } \\
\text { metametamemetasiststatus }\end{array}$ & & & & 0.315 \\
\hline Positive & 4 & 2 & 6 & \\
\hline Negative & 3 & 6 & 9 & \\
\hline Pathological grading & & & & 0.041 \\
\hline II & 2 & 7 & 9 & \\
\hline III & 5 & 1 & 6 & \\
\hline Clinical stage & & & & 0.315 \\
\hline I & 3 & 6 & 9 & \\
\hline II & 4 & 2 & 6 & \\
\hline
\end{tabular}
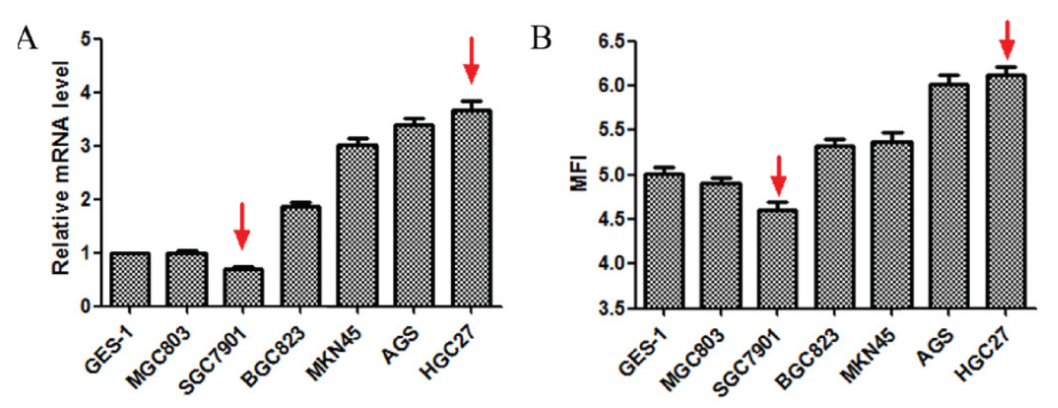

C

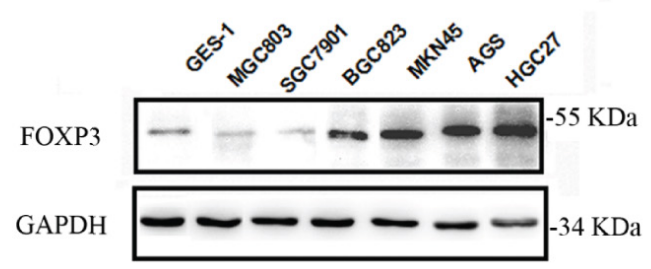

Fig. 3. FOXP3 expression in gastric cancer cells. (A) FOXP3 mRNA was detected in both GC cells and the normal gastric epithelial cell line (GES-1) by RT-PCR. Red arrows indicate expression of FOXP4 mRNA in HGC27 and SGC7901 cells. (B) FOXP3 protein was detected in both GC cells and GES-1 by flow cytometry. Expression of FOXP3 protein in HGC27 and SGC7901 cells are indicated by the red arrow. (C) FOXP3 protein was detected in both GC cells and GES-1 by western blot. 


\section{Cellular Physiology Cell Physiol Biochem 2017;42:1739-1754 \begin{tabular}{ll|l} 
DOI: 10.1159/000479442, & $\begin{array}{l}\text { @ 2017 The Author(s). Published by S. Karger AG, Basel } \\
\text { www.karger.com/cpb }\end{array}$ \\
\hline
\end{tabular}

Fig. 4. Localization of FOXP3 in GC cells and GES-1. Laser confocal microscopy showed FOXP3 expression in HGC27, SGC7901, and GES-1 cells (400X magnification).

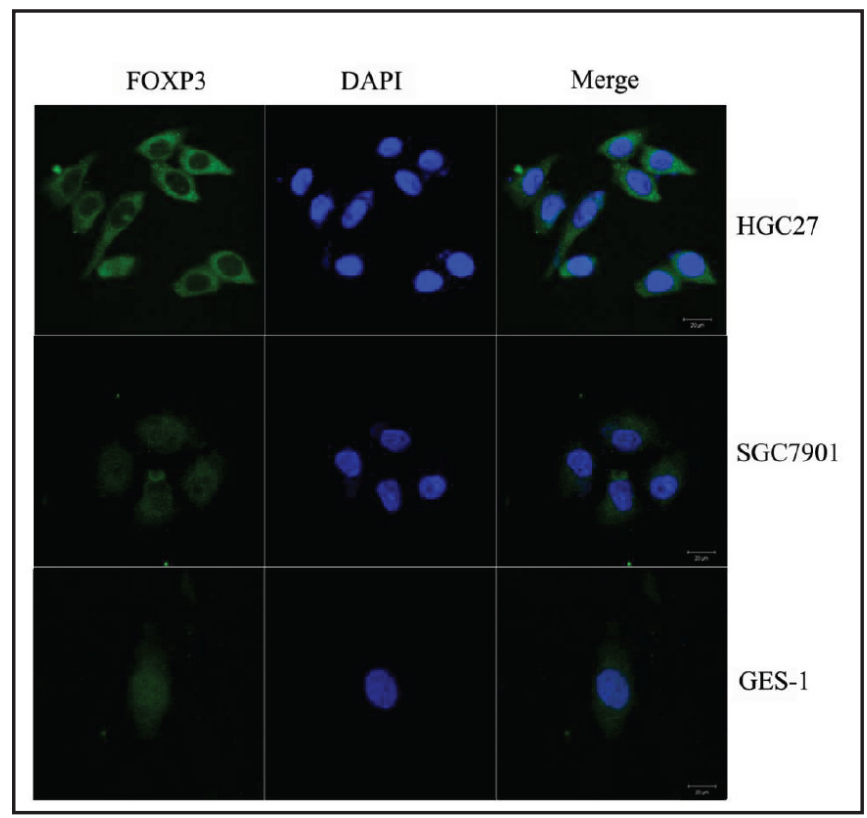

A

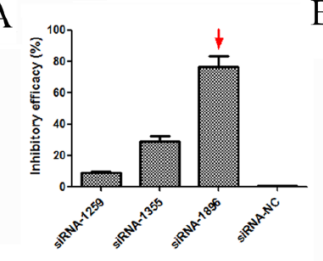

$\mathrm{D}$

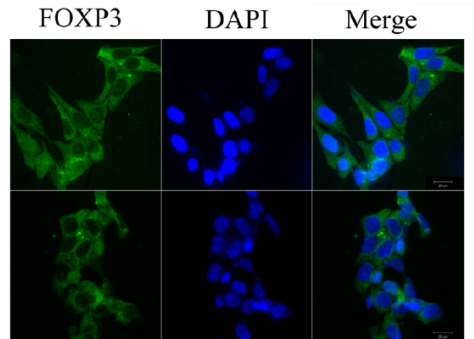

B

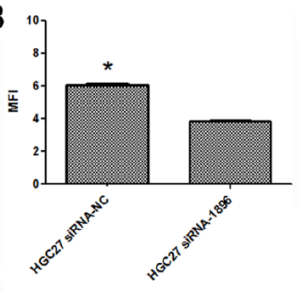

$\mathrm{C}$

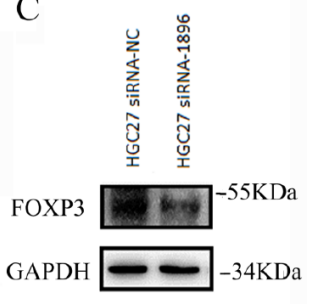

HGC27 SiRNA-NC

HGC27 siRNA-1896

Fig. 5. Inhibitory efficacy of FOXP3 specific siRNAs. (A) Inhibitory efficacy of three FOXP3 specific siRNAs on FOXP3 expression at the mRNA level. siRNA-1896 is indicated by the red arrow. (B) Expression of FOXP3 protein in siRNA-1896 transfected HGC27 cells, as analyzed by flow cytometry $* \mathrm{P}<0.05$, compared with HGC27 cells transfected with siRNA-1896. (C) Western blot of FOXP3 protein expression in HGC27 cells following transfection with siRNA-1896. The predicted MW is $47 \mathrm{KDa}$ for FOXP3 and 36 KDa for GAPDH (D) Laser confocal microscopy showing cytoplasmic expression of FOXP3 in HGC27 cells, 400x magnification.

with that in GES-1, including HGC27, AGS, MKN45, BGC823. In addition, the expressional level of FOXP3 was found to be decreased in moderately and well differentiated cell lines by comparison with that in GES-1, including MGC803 and SGC7901. Among these cells, HGC27 expressed the highest level of FOXP3 at both the transcriptional and translational levels, and SGC7901 expressed the lowest level of FOXP3 at both the transcriptional and translational levels (Fig. 3). We also found that FOXP3 was expressed in both the cytoplasm and the nucleus of GES-1 and SGC7901 cells, whereas it was mainly expressed in the cytoplasm of HGC27 cells, as shown by laser confocal microscopy (Fig. 4). 
Fig. 6. FOXP3 knockdown inhibited the proliferation, migration, and invasion of GC cells. (A) CCK8 assay and (B) plate clone assay showing the effect of FOXP3 knockdown on proliferation of HGC27 cells, *P < 0.05 , compared with HGC27 transfected siRNA-1896. (C) Transwell assay and (D) wound healing assay show the effect of FOXP3 knockdown on migration of HGC27 cells, ${ }^{*} \mathrm{P}<0.05$, compared with the HGC27 transfected siRNA-1896. (E) Transwell assay on HGC27 cells with FOXP3, * $\mathrm{P}<0.05$, compared with HGC27 transfected siRNA-1896.

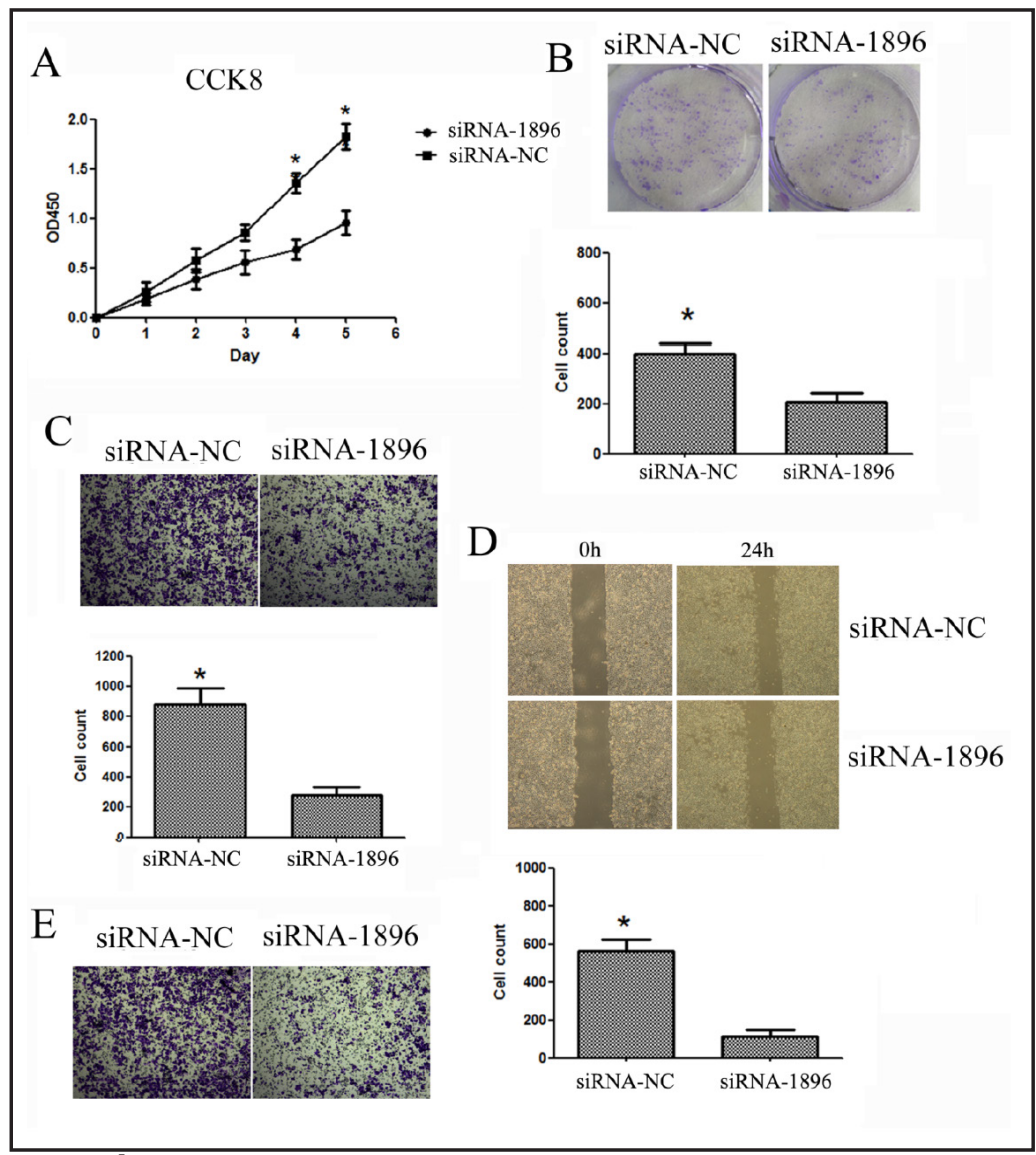

Proliferation, migration, and invasion

To explore the effects of FOXP3 on gastric cancer, HGC27 cells were chosen for FOXP3 knockdown, as it exhibited the highest expression level of FOXP3. As shown in Fig. 5A, among the three synthesized FOXP3-specific siRNAs, siRNA-1896 demonstrated the highest efficacy in terms of inhibition of FOXP3 expression at the mRNA level. The inhibitory role of siRNA-1896 on protein expression of FOXP3 was further confirmed by flow cytometry (Fig. 5B), western blot (Fig. 5C), and laser confocal microscopy (Fig. 5D). Therefore, siRNA-1896 was used for follow-up experiments. As shown in Fig. 6, knockdown of FOXP3 significantly inhibited proliferation of HGC27 cells, as demonstrated by the CCK8 (Fig. 6A) and plate clone assays (Fig. 6B). We further determined the role of FOXP3 in cell motility via transwell (Fig. 6C) and wound healing assays (Fig. 6D). Results showed that FOXP3 knockdown resulted in significantly decreased numbers of migrating HGC27 cells, and reduced the migration capacity of HGC27 cells. In addition, the number of invasive HGC27 cells was significantly decreased as compared to that of control cells (Fig. 6E). Taken together, our data suggested that FOXP3 knockdown can inhibit GC cell proliferation, migration, and invasion.

FOXP3 overexpression promoted GC cell proliferation, migration, and invasion

To further investigate the effects of FOXP3 on the malignant activities of GC cells, FOXP3 was overexpressed in SGC7901 cells, as it demonstrated the lowest FOXP3 expression. Efficacy of the overexpression system was confirmed by a series of assays, including RT-PCR (Fig. 7A), flow cytometry (Fig. 7B), western blot (Fig. 7C), and laser confocal microscopy (Fig. 7D). RNA interference assays using siRNA-1896 reduced the expression levels of FOXP3. In addition, laser confocal microscopy indicated that FOXP3 was overexpressed mainly in the nuclei of SGC7901 cells, and that RNA interference mainly retrieved the expression of FOXP3 in the nuclei. As shown in Fig. 8, CCK8 (Fig. 8A) and plate clone assays (Fig. 8B) indicated that overexpression of FOXP3 promotes proliferation of SGC7901 cells. Transwell (Fig. 
Fig. 7. The overexpression of FOXP3 in SGC7901. Expression level of FOXP3 analyzed via (A) RT-PCR, (B) flow cytometry, and (C) western blot in SGC7901 FOXP3 cells transfected with FOXP3-overexpressing lentilvirus. Upregulated FOXP3 expression in SGC7901 FOXP3 cells retrieved partially by RNA interference with siRNA-1896. The predicted MW is $47 \mathrm{KDa}$ for FOXP3 and $36 \mathrm{KDa}$ for GAPDH. $*$ P $<0.05$, compared with SGC7901 control cells. ${ }^{* *} \mathrm{P}<0.05$, compared with SGC7901 FOXP3 cells. (D) Laser confocal microscopy showing FOXP3 overexpression in the nuclei of SGC7901 FOXP3 cells, which can be reduced by siRNA-1896.

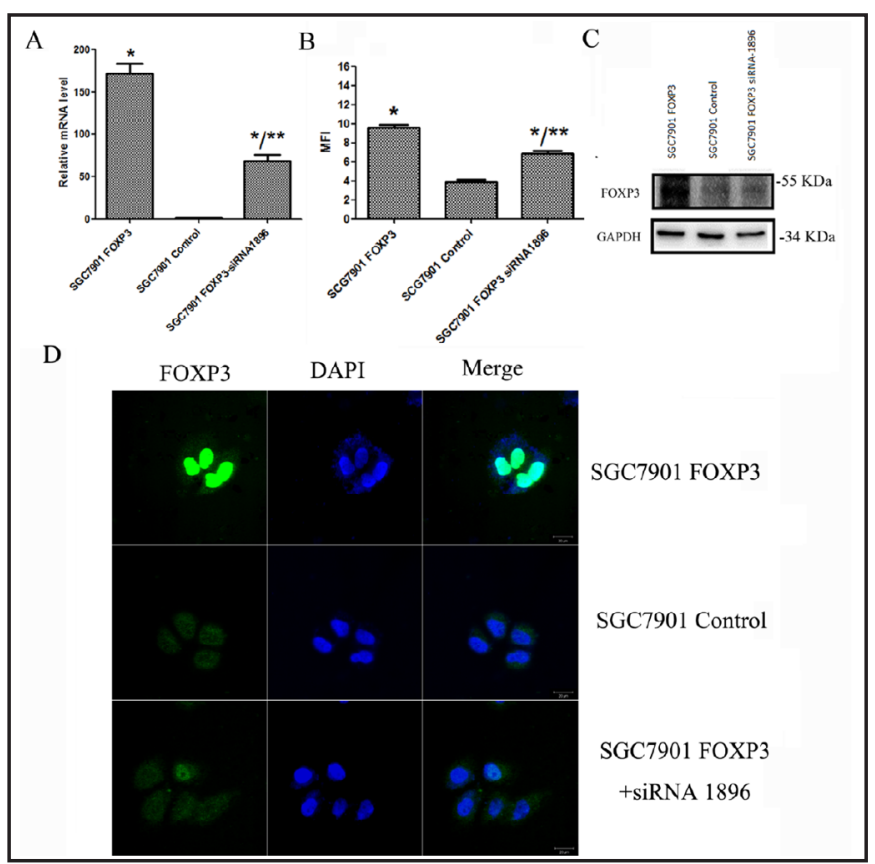

Fig. 8. FOXP3 overexpression promoted the proliferation, migration, and invasion of GC cells. (A) CCK8 and (B) plate clone assay showed that FOXP3 overexpression promoted the proliferation of SGC7901 cells, and RNA interference can retrieve these effects on FOXP3 overexpressing SGC7901 cells, *: $\mathrm{P}<0.05$, compared with SGC7901 control cells, **: P<0.05, compared with SGC7901 FOXP3 cells. (C) Transwell assay and (D) wound healing assay indicated that FOXP3 overexpression promoted the migration of SGC7901 cells, and RNA interference can retrieve these effects on FOXP3 overexpressing SGC7901 cells, *: P<0.05, compared with SGC7901 control cells, **: P<0.05, compared with SGC7901 FOXP3 cells. (E) Transwell assay indicated that FOXP3 overexpression promoted the invasive capacity of SGC7901 cells, *: P<0.05, com-

A
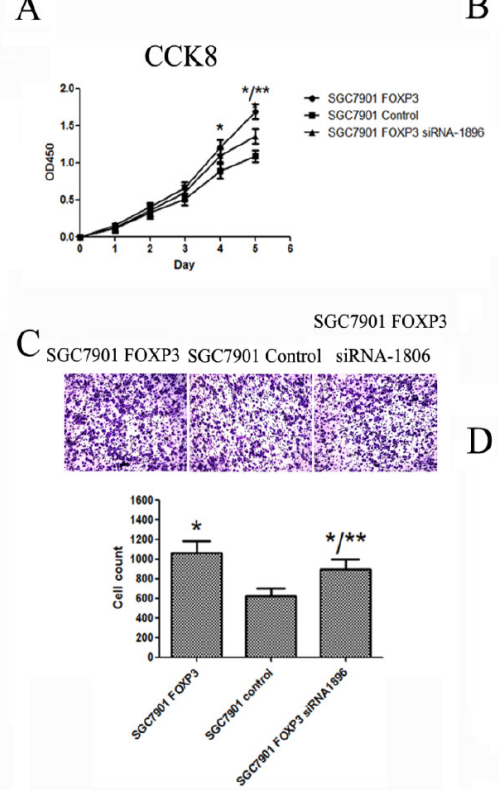

E

SGC7901 FOXP3

$E_{\text {SGC7901 FOXP3 SGC7901 Control siRNA-1806 }}$

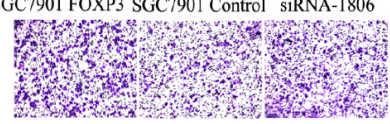

B SGC7901 FOXP3 SGC7901 Control 501 FOXP

SGC7901 FOXP3 SGC7901 Control siRNA-1896
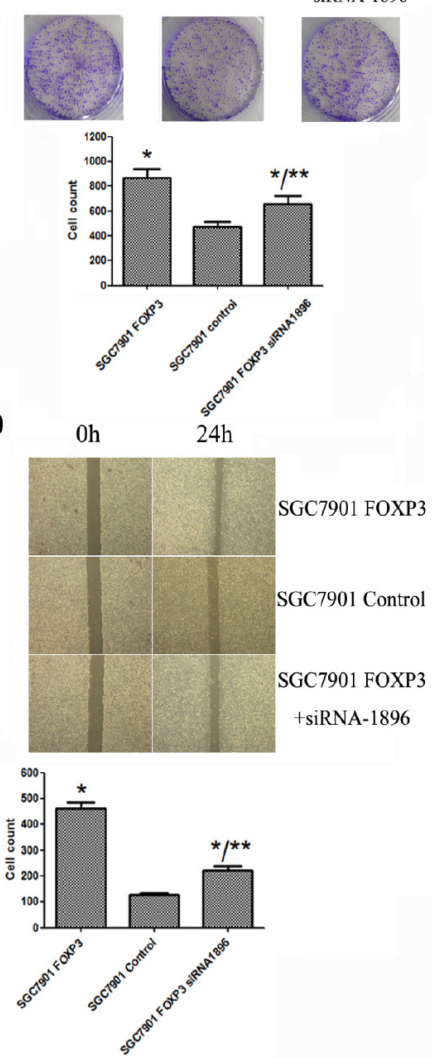

pared with SGC7901 control cells, ${ }^{* *}$ : P<0.05, compared with SGC7901 FOXP3 cells.

8C) and wound healing assays (Fig. 8D) showed that FOXP3 overexpression results in an increased number of migrating SGC7901 cells, and promotes migration of SGC7901 cells. 


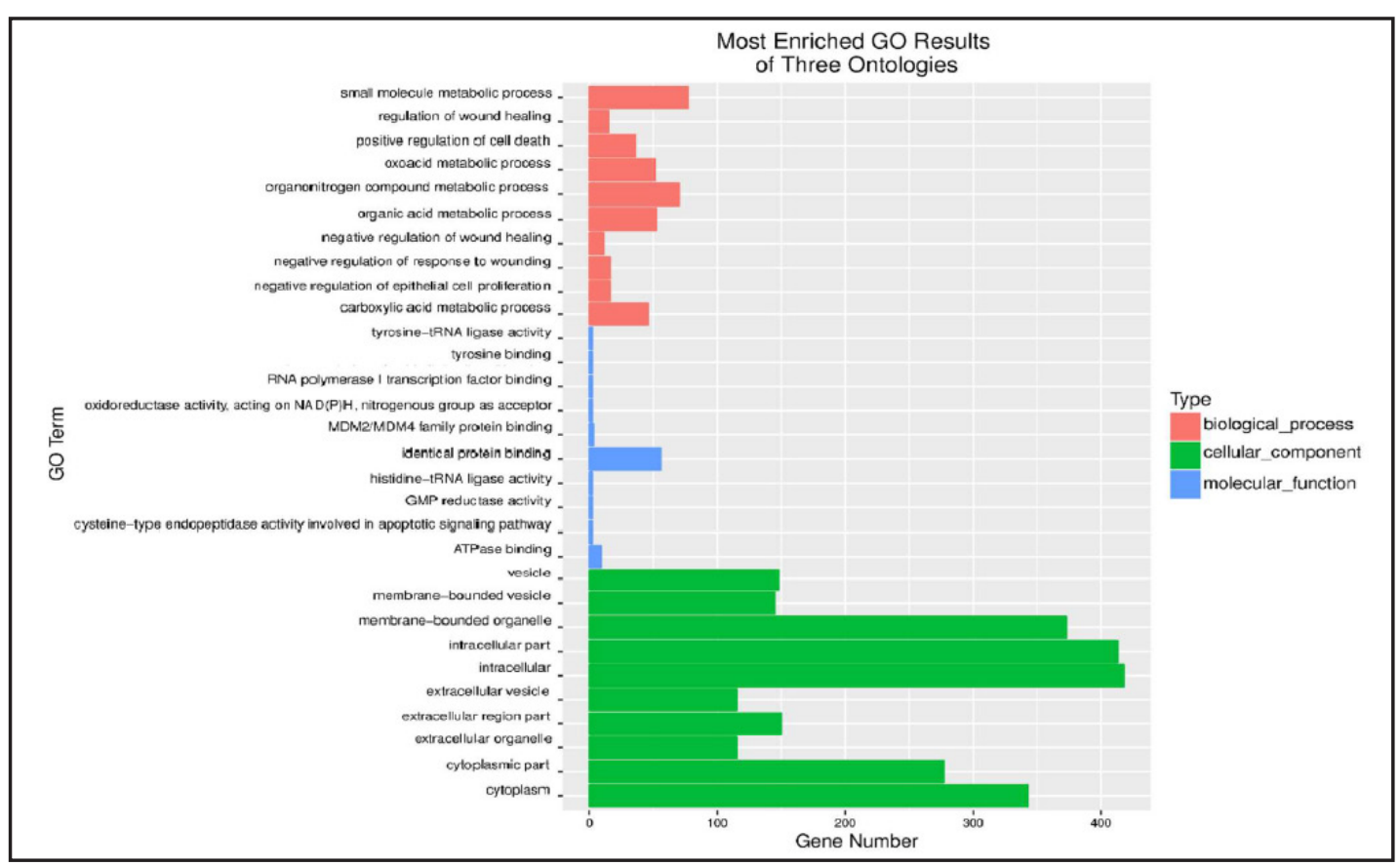

Fig. 9. The most enriched GO results of three ontologies by high-throughput RNA-sequencing and computational analysis. The most enriched GO results are listed, and the differentially expressed genes are categorized into three types of ontologies, including biological process (bar in pink), cellular component (bar in green), and molecular function (bar in blue).

Fig. 10. The top 10 enriched pathways. The top 10 enriched pathways are listed. The size of the dot represents the number of genes participating in the pathway, the color represents the $Q$ value, and the $\mathrm{X}$-axis represents the rich factor.

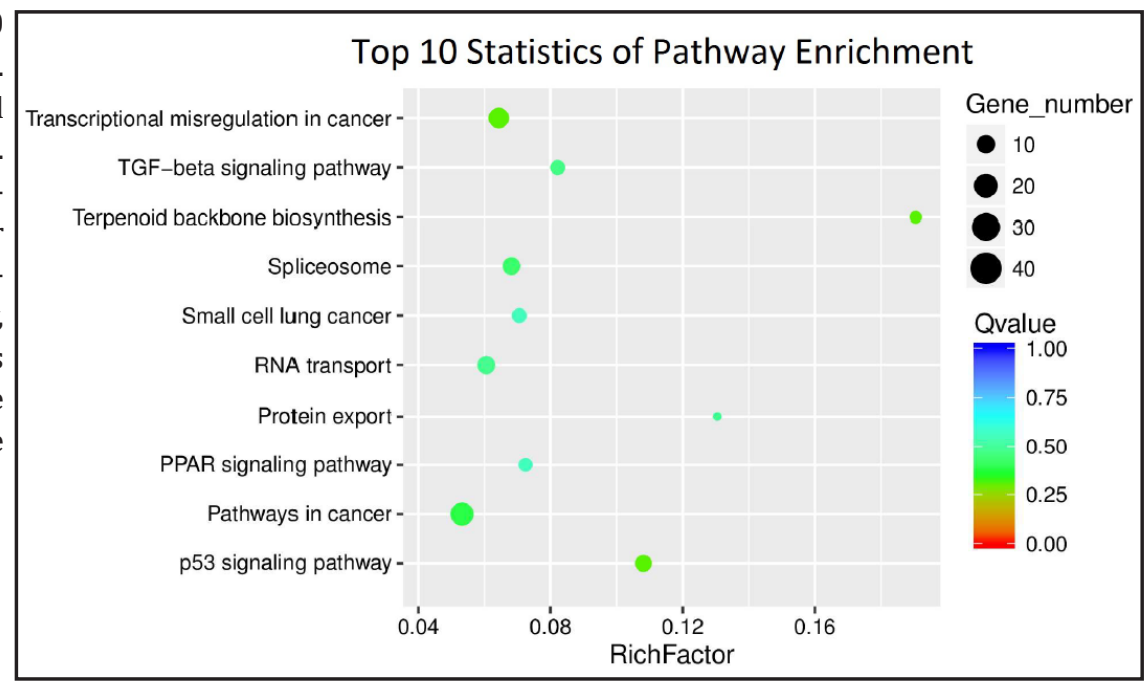

The transwell assay (Fig. 8E) demonstrated that overexpression of FOXP3 can markedly increase the number of invading SGC7901 cells. Additionally, RNA interference assays using siRNA1896 further confirmed that knockdown of FOXP3 in FOXP3-overexpressing SGC7901 cells can partially inhibit the effects of FOXP3 on the proliferation, migration, and invasion capacity of GC cells. Therefore, our data suggested that upregulation of FOXP3 can promote proliferation, migration, and invasion of GC cells.

High-throughput RNA-sequencing revealed potential molecules and signaling pathways associated with effects of tumoral FOXP3 on GC

The results discussed above indicated that tumoral FOXP3 plays an important role on GC growth and metastasis. However, the underlying mechanisms behind the observed phenomenon remain elusive. To further elucidate the mechanism underlying the effect of 


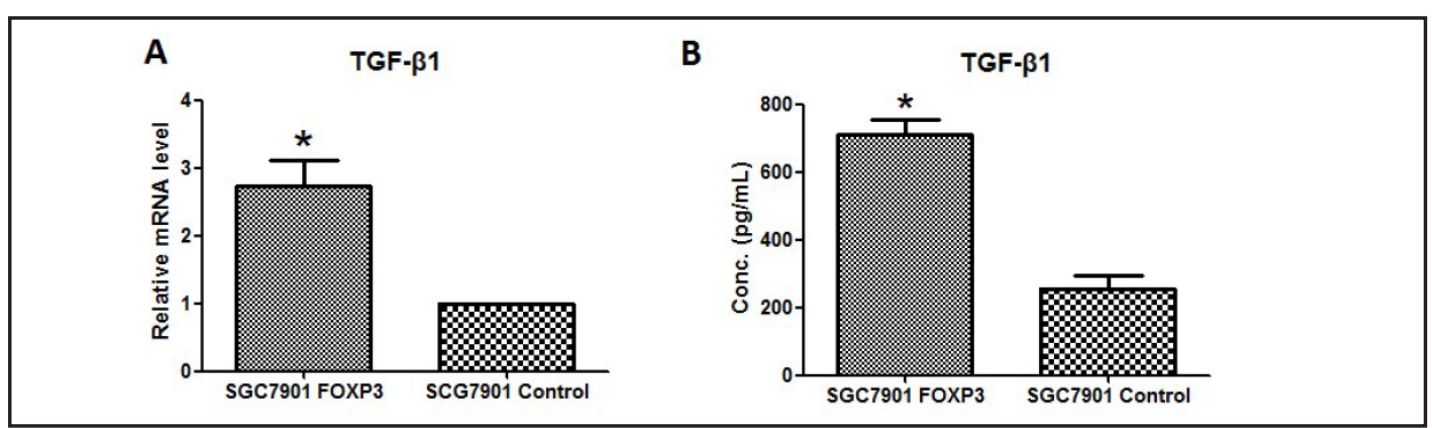

Fig. 11. Changes in the expression of TGF- $\beta 1$ in SGC7901 after FOXP3 overexpression. RT-PCR and ELISA results showing that elevated FOXP3 increases TGF- $\beta 1$ expression and secretion in SGC7901 cells, ${ }^{*} \mathrm{P}<0.05$, as compared with SGC7901 control cells.

FOXP3 on GC, we utilized high-throughput RNA-sequencing and computational analysis to screen differentially expressed genes in SGC7901 FOXP3 (FOXP3-overexpressing SGC7901 cells) and SGC7901 control cells (pEX-3 transfected SGC7901 cells), as well as the potential signaling pathways involved. Results showed that there were 562 differentially expressed genes between these cells $(P<0.05)$, among which, 158 genes were upregulated $(23$ genes with 5-fold difference), and 404 genes were downregulated (48 genes with $>5$-fold difference), in FOXP3-overexpressing SGC7901 cells. The most enriched GO results are listed in Fig. 9. Based on these differentially expressed genes, potential pathways involved in the process were proposed, including the TGF- $\beta$ pathway. The top 10 enriched pathways are listed in Fig. 10.

It is well known that the TGF- $\beta$ pathway participates in tumorigenesis and cancer development. Therefore, we further examined TGF- $\beta 1$ expression and secretion via RT-PCR and ELISA. As shown in Fig. 11, TGF- $\beta 1$ expression was significantly upregulated in FOXP3 overexpressing SGC7901 cells at the transcriptional level as compared to that in control cells (Fig. 11A). Furthermore, TGF- $\beta 1$ secretion was also increased in FOXP3 overexpressing SGC7901 cells as compared to that in control cells (Fig. 11B).

\section{Discussion}

In this study, we found that both GC and normal gastric epithelial cells (GES-1) express the FOXP3 protein. Moreover, FOXP3 was highly expressed in undifferentiated and poorly differentiated GC cell lines, whereas relatively low expression was found in moderately and well differentiated GC cell lines, suggesting that expression levels of FOXP3 may be associated with the degree of GC differentiation. Interestingly, localization of FOXP3 was found to be different across cell types; HGC 27 cells expressed FOXP3 mainly in the cytoplasm, whereas SGC7901 and GES-1 cells expressed both cytoplasmic and nuclear FOXP3. We also observed FOXP3 expression in both GC and para-carcinoma tissues. Expression of FOXP3 in GC tissues was higher as compared to that in para-carcinoma tissues, which was consistent with previous studies [31, 35]. Additionally, expression levels of FOXP3 was associated with pathological grading of GC, which was also consistent with results from a previous study by Jiang et al. [35]. This suggested that FOXP3 expression is associated with the degree of GC differentiation, No correlation was found between FOXP3 expression and lymph node metastasis in our study. However, Wang et al. found that elevated FOXP3 expression is correlated with increased lymph node metastasis in gastric cancer [31]. The inconsistent results may be due to the small sample size of our study, which may have introduced some statistical bias. In addition, detection of FOXP3 was conducted in metastatic lymph node tissues in the study by Wang et al.; therefore, it is worthwhile to examine FOXP3 expression not only in cancer tissues but also in metastatic lymph node tissues to further clarify the correlation between FOXP3 expression and lymph node metastasis.

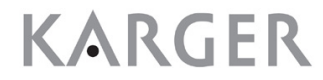


We found that in para-carcinoma tissues, FOXP3 expression was mostly restricted to the cytoplasm. In GC tissues, however, FOXP3 can be detected in either the cytoplasm or both the cytoplasm and the nucleus. The heterogeneous localization of FOXP3 protein in GC was in accordance with previous studies in breast cancer [14,36] and pancreatic cancer [25]. Ectopic expression of tumoral FOXP3 may be because of the different somatic mutations in FOXP3 that are found in different tumor tissues and cell lines [12,17]. Similar mutations were also found in IPEX patients that exhibited altered FOXP3 localization and function [37]. Previous studies in breast cancer showed that reduced expression of nuclear FOXP3 may be a predictive factor of breast cancer progression and metastasis. Another study by Merlo et al. reported that cytoplasmic FOXP3 expression is associated with lymph node metastases, distant relapse, and poor overall survival of breast cancer patients [14]. All these data above indicated that changes in FOXP3 expression levels and localization may be associated with its function and effects on malignant behaviors in cancer.

With respect to the effects of FOXP3 on tumor cells, published data show conflicting results in different tumors types. Even in the same type of cancer, the results are inconsistent. Ladoire et al. demonstrated that breast cancer patients with elevated FOXP3 expression had significantly lower axillary lymph node involvement [38], and elevated FOXP3 expression was associated with better relapse-free and overall survival in breast cancer patients treated with neoadjuvant chemotherapy [36]. This suggested that FOXP3 plays a tumor-suppressing role in breast cancer. On the contrary, the study by Merlo et al. suggested that FOXP3 expression is significantly associated with lymph node positivity, and may be a poor prognostic factor in breast cancers [14]. One difference in the methodology between the two studies was that tumors analyzed by Ladoire et al. were all treated with neoadjuvant therapy, whereas those examined by Merlo were untreated. Therefore, FOXP3 in breast cancer is likely to be associated with poor prognosis as described by Merlo because neoadjuvant chemotherapy is known to modify the immune system, and possibly its interaction with tumor cells. To characterize the effects of FOXP3 on malignancy of gastric cancer, we conducted a series of assays in vitro to measure the parameters of malignant behavior. The results of our study showed that FOXP3 is indeed capable of promoting GC proliferation, migration, and invasion in vitro. To our knowledge, our study is the first to report the demonstration of FOXP3 as a stimulator for proliferation, migration, and invasion in GC, which was inconsistent with results reported by Hao et al. and other studies [26, 39]. This may be because of the different GC cell lines used in the studies. Furthermore, localization of FOXP3 in GC cell lines in these studies has not been reported; ectopic localization of FOXP3 may be associated with its functions in GC cells.

To date, the exact mechanisms underlying the effect of FOXP3 on malignant cells is not very clear. Previous studies indicated that FOXP3 can reduce the migratory and invasive capacity of malignant ovarian cells by downregulating MMP-2 and uPA, as well as mTOR and NF- $\mathrm{KB}$ [15]. Another study in breast cancer showed that FOXP3 may regulate cancer invasion and metastasis by regulating the expression of chemokine receptors, such as CXCR4 $[40,41]$. A study in gastric cancer revealed that FOXP3 is a tumor-suppressor that inhibits $\mathrm{NF} \kappa \mathrm{B}$ activity, and thereby inhibits COX2 expression [29]. Another study in gastric cancer suggested that FOXP3 acts through the Hippo pathway [27]. These inconsistent results may be due to differences in tumor type and FOXP3 localization. Therefore, in this study, we utilized high-throughput RNA-sequencing and computational analysis to reveal the exact mechanisms of FOXP3 function and its potential molecular targets. Results indicated that several pathways may be associated with the effects of FOXP3 on malignant activities in GC, including the TGF- $\beta$ signaling pathway. Further studies by RT-PCR and ELISA confirmed the increased TGF- $\beta 1$ expression and secretion in FOXP3 overexpressing cells, suggesting that the TGF- $\beta$ pathway may be an important mechanism by which FOXP3 regulates gastric cancer development.

It was reported that TGF- $\beta$ not only participates in tumorigenesis and development of cancer $[42,43]$, but also regulates the immune response as a key immune inhibitory cytokine [44], resulting in immune escape within the tumor microenvironment. Treg cells were also 
shown to play a significant role in the suppression of local antitumor immune responses through TGF- $\beta$ secretion [45]. This may explain why an increased number of FOXP $3^{+}$cells within the tumor microenvironment have been associated with a high risk of recurrence and poor overall survival. Although the role of Treg-derived TGF- $\beta$ on immune response is well known, the exact role of tumor-derived TGF- $\beta$ is not very clear. Xue and Jiang suggested that FOXP3 expression may be an important mechanism of immune escape in gastric cancer $[35,39]$. Here we hypothesized that FOXP3 can increase TGF- $\beta$ expression and secretion, which can further exhibit an inhibitory role on anti-tumor immune responses via the TGF- $\beta$ pathway; in-depth work is needed to verify our hypothesis.

There were several limitations in the current study. First, only in vitro assays were conducted to examine the effects of FOXP3 on GC cells. In future studies, tumor-bearing mice will be used to confirm the results of the current study. Second, the sample size of the gastric cancer tissues was very small, which may have generated a bias during statistical analysis. In addition, survival data and its correlation with FOXP3 expression have not been investigated in this study, which will be the next step in our research. Third, results of high-throughput RNA-sequencing were not evaluated and verified in depth; however, these results will narrow down the scope of future mechanistic studies.

In conclusion, our study indicated that the expression level and localization of FOXP3 may be associated with its functions in cancer. In GC, FOXP3 expression was found to be associated with the degree of GC differentiation, and was a stimulator of cell proliferation, migration, and invasion. Additional research needs to be conducted to identify and validate the potential molecules and signaling pathways involved, which will enable us to develop a promising approach for gastric cancer therapy.

\section{Acknowledgements}

This study was funded by the National Natural Science Foundation of China (81572362, 81272712); the National Natural Science Foundation Project of International Cooperation(NSFC-NIH, 81361120398); the Primary Research \& Developement Plan of Jiangsu Province (BE2016786); the Program for Development of Innovative Research Team in the First Affiliated Hospital of NJMU; the Priority Academic Program Development of Jiangsu Higher Education Institutions (PAPD, JX10231801); 333 Project of Jiangsu Province (BRA2015474); the youth foundation of Jiangsu Province Health Bureau (BK20161062); Jiangsu Key Medical Discipline (General Surgery); Jiangsu Key Lab of Cancer Biomarkers, Prevention and Treatment, Collaborative Innovation Center for Cancer Personalized Medicine, Nanjing Medical University

\section{Ethical approval}

This article does not contain any studies with human participants or animals performed by any of the authors.

\section{Disclosure Statement}

The authors declare no conflict of interest.

\section{References}

1 Han C, Zhou Y, An Q, Li F, Li D, Zhang X, Yu Z, Zheng L, Duan Z, Kan Q: MicroRNA-1 (miR-1) inhibits gastric cancer cell proliferation and migration by targeting MET. Tumour Biol 2015;36:6715-6723.

-2 Best LM, Mughal M, Gurusamy KS: Laparoscopic versus open gastrectomy for gastric cancer. Cochrane Database Syst Rev 2016;3:CD011389.

-3 Deng K, Wang H, Shan T, Chen Y, Zhou H, Zhao Q, Xia J: Tristetraprolin inhibits gastric cancer progression through suppression of IL-33. Sci Rep 2016;6:24505. 


\section{Cellular Physiology Cell Physiol Biochem 2017;42:1739-1754 and Biochemistry Published \begin{tabular}{l|l} 
DOI: 10.1159/000479442 & $\begin{array}{l}\text { C } 2017 \text { The Author(s). Published by S. Karger AG, Basel } \\
\text { www.karger.com/cpb }\end{array}$
\end{tabular}}

Zhang et al.: The Role of Tumoral FOXP3 in Gastric Cancer

-4 Szasz AM, Lanczky A, Nagy A, Forster S, Hark K, Green JE, Boussioutas A, Busuttil R, Szabo A, Gyorffy B: Cross-validation of survival associated biomarkers in gastric cancer using transcriptomic data of 1,065 patients. Oncotarget 2016;7:49322-49333.

-5 Brunkow ME, Jeffery EW, Hjerrild KA, Paeper B, Clark LB, Yasayko SA, Wilkinson JE, Galas D, Ziegler SF, Ramsdell F: Disruption of a new forkhead/winged-helix protein, scurfin, results in the fatal lymphoproliferative disorder of the scurfy mouse. Nat Genet 2001;27:68-73.

-6 Wildin RS, Ramsdell F, Peake J, Faravelli F, Casanova JL, Buist N, Levy-Lahad E, Mazzella M, Goulet O, Perroni L, Bricarelli FD, Byrne G, McEuen M, Proll S, Appleby M, Brunkow ME: X-linked neonatal diabetes mellitus, enteropathy and endocrinopathy syndrome is the human equivalent of mouse scurfy. Nat Genet 2001;27:18-20.

7 Schubert LA, Jeffery E, Zhang Y, Ramsdell F, Ziegler SF: Scurfin (FOXP3) acts as a repressor of transcription and regulates T cell activation. J Biol Chem 2001;276:37672-37679.

8 Hori S, Nomura T, Sakaguchi S: Control of regulatory T cell development by the transcription factor Foxp3. Science 2003;299:1057-1061.

-9 Hori S, Sakaguchi S: Foxp3: a critical regulator of the development and function of regulatory T cells. Microbes Infect 2004;6:745-751.

-10 Sakaguchi S, Ono M, Setoguchi R, Yagi H, Hori S, Fehervari Z, Shimizu J, Takahashi T, Nomura T: Foxp3+ CD25+ CD4+ natural regulatory T cells in dominant self-tolerance and autoimmune disease. Immunol Rev 2006;212:8-27.

11 Coffer PJ, Burgering BM: Forkhead-box transcription factors and their role in the immune system. Nat Rev Immunol 2004;4:889-899.

12 Zuo T, Wang L, Morrison C, Chang X, Zhang H, Li W, Liu Y, Wang Y, Liu X, Chan MW, Liu JQ, Love R, Liu CG, Godfrey V, Shen R, Huang TH, Yang T, Park BK, Wang CY, Zheng P, Liu Y: FOXP3 is an X-linked breast cancer suppressor gene and an important repressor of the HER-2/ErbB2 oncogene. Cell 2007;129:1275-1286.

13 Zuo T, Liu R, Zhang H, Chang X, Liu Y, Wang L, Zheng P, Liu Y: FOXP3 is a novel transcriptional repressor for the breast cancer oncogene SKP2. J Clin Invest 2007;117:3765-3773.

$\checkmark 14$ Merlo A, Casalini P, Carcangiu ML, Malventano C, Triulzi T, Menard S, Tagliabue E, Balsari A: FOXP3 expression and overall survival in breast cancer. J Clin Oncol 2009;27:1746-1752.

15 Zhang HY, Sun H: Up-regulation of Foxp3 inhibits cell proliferation, migration and invasion in epithelial ovarian cancer. Cancer Lett 2010;287:91-97.

16 Chen GY, Chen C, Wang L, Chang X, Zheng P, Liu Y: Cutting edge: Broad expression of the FoxP3 locus in epithelial cells: a caution against early interpretation of fatal inflammatory diseases following in vivo depletion of FoxP3-expressing cells. J Immunol 2008;180:5163-5166.

17 Wang L, Liu R, Li W, Chen C, Katoh H, Chen GY, McNally B, Lin L, Zhou P, Zuo T, Cooney KA, Liu Y, Zheng P: Somatic single hits inactivate the X-linked tumor suppressor FOXP3 in the prostate. Cancer Cell 2009;16:336-346.

18 Katoh H, Qin ZS, Liu R, Wang L, Li W, Li X, Wu L, Du Z, Lyons R, Liu CG, Liu X, Dou Y, Zheng P, Liu Y: FOXP3 orchestrates H4K16 acetylation and H3K4 trimethylation for activation of multiple genes by recruiting MOF and causing displacement of PLU-1. Mol Cell 2011;44:770-784.

19 Li W, Wang L, Katoh H, Liu R, Zheng P, Liu Y: Identification of a tumor suppressor relay between the FOXP3 and the Hippo pathways in breast and prostate cancers. Cancer Res 2011;71:2162-2171.

20 Liu R, Wang L, Chen G, Katoh H, Chen C, Liu Y, Zheng P: FOXP3 up-regulates p21 expression by sitespecific inhibition of histone deacetylase 2/histone deacetylase 4 association to the locus. Cancer Res 2009;69:2252-2259.

-21 Triulzi T, Tagliabue E, Balsari A, Casalini P: FOXP3 expression in tumor cells and implications for cancer progression. J Cell Physiol 2013;228:30-35.

-22 Zeng C, Yao Y, Jie W, Zhang M, Hu X, Zhao Y, Wang S, Yin J, Song Y: Up-regulation of Foxp3 participates in progression of cervical cancer. Cancer Immunol Immunother 2013;62:481-487.

23 Wang G, Liu G, Liu Y, Li X, Su Z: FOXP3 expression in esophageal cancer cells is associated with poor prognosis in esophageal cancer. Hepatogastroenterology 2012;59:2186-2191.

24 Gerber AL, Munst A, Schlapbach C, Shafighi M, Kiermeir D, Husler R, Hunger RE: High expression of FOXP3 in primary melanoma is associated with tumour progression. Br J Dermatol 2014;170:103-109.

25 Hinz S, Pagerols-Raluy L, Oberg HH, Ammerpohl O, Grussel S, Sipos B, Grutzmann R, Pilarsky C, Ungefroren H, Saeger HD, Kloppel G, Kabelitz D, Kalthoff H: Foxp3 expression in pancreatic carcinoma cells as a novel mechanism of immune evasion in cancer. Cancer Res 2007;67:8344-8350. 


\section{Cellular Physiology Cell Physiol Biochem 2017;42:1739-1754 \begin{tabular}{l|l} 
and Biochemistry Published online: July 25, 2017 & $\begin{array}{l}\text { (c) } 2017 \text { The Author(s). Published by S. Karger AG, Basel } \\
\text { www.karger.com/cpb }\end{array}$
\end{tabular}}

Zhang et al.: The Role of Tumoral FOXP3 in Gastric Cancer

26 Ma GF, Chen SY, Sun ZR, Miao Q Liu YM, Zeng XQ, Luo TC, Ma LL, Lian JJ, Song DL: FoxP3 inhibits proliferation and induces apoptosis of gastric cancer cells by activating the apoptotic signaling pathway. Biochem Biophys Res Commun 2013;430:804-809.

27 Suh JH, Won KY, Kim GY, Bae GE, Lim SJ, Sung JY, Park YK, Kim YW, Lee J: Expression of tumoral FOXP3 in gastric adenocarcinoma is associated with favorable clinicopathological variables and related with Hippo pathway. Int J Clin Exp Pathol 2015;8:14608-14618.

-28 Ma GF, Miao Q, Liu YM, Gao H, Lian JJ, Wang YN, Zeng XQ, Luo TC, Ma LL, Shen ZB, Sun YH, Chen SY: High FoxP3 expression in tumour cells predicts better survival in gastric cancer and its role in tumour microenvironment. Br J Cancer 2014;110:1552-1560.

29 Hao Q Zhang C, Gao Y, Wang S, Li J, Li M, Xue X, Li W, Zhang W, Zhang Y: FOXP3 inhibits NF-kappaB activity and hence COX2 expression in gastric cancer cells. Cell Signal 2014;26:564-569.

30 Hao Q Li W, Zhang C, Qin X, Xue X, Li M, Shu Z, Xu T, Xu Y, Wang W, Zhang W, Zhang Y: TNFalpha induced FOXP3-NFkappaB interaction dampens the tumor suppressor role of FOXP3 in gastric cancer cells. Biochem Biophys Res Commun 2013;430:436-441.

31 Wang LH, Su L, Wang JT: Correlation between elevated FOXP3 expression and increased lymph node metastasis of gastric cancer. Chin Med J (Engl) 2010;123:3545-3549.

-32 Yoshii M, Tanaka H, Ohira M, Muguruma K, Iwauchi T, Lee T, Sakurai K, Kubo N, Yashiro M, Sawada T, Hirakawa K: Expression of Forkhead box P3 in tumour cells causes immunoregulatory function of signet ring cell carcinoma of the stomach. Br J Cancer 2012;106:1668-1674.

-33 Guo G, He Z, Shi Z: Correlation between FOXP3 expression and gastric cancer. Oncol Lett 2016;12:15541558.

34 Konno R, Yamakawa H, Utsunomiya H, Ito K, Sato S, Yajima A: Expression of survivin and Bcl-2 in the normal human endometrium. Mol Hum Reprod 2000;6:529-534.

-35 Jiang C, Wang W, Yan W, Zhang Y, Yang J, Zhang S, Zhang C, Zhang W, Han W, Wang J, Zhang YQ: Clinical implications and characteristics of factor forkhead box protein 3 in gastric cancer. Exp Ther Med 2011;2:667-673.

-36 Ladoire S, Arnould L, Mignot G, Coudert B, Rebe C, Chalmin F, Vincent J, Bruchard M, Chauffert B, Martin F, Fumoleau P, Ghiringhelli F: Presence of Foxp3 expression in tumor cells predicts better survival in HER2overexpressing breast cancer patients treated with neoadjuvant chemotherapy. Breast Cancer Res Treat 2011;125:65-72.

37 Ziegler SF: FOXP3: of mice and men. Annu Rev Immunol 2006;24:209-226.

38 Ladoire S, Mignot G, Dalban C, Chevriaux A, Arnould L, Rebe C, Apetoh L, Boidot R, Penault-Llorca F, Fumoleau P, Roche H, Spielmann M, Levy C, Lortholary A, Eichler F, Mesleard C, Bonnetain F, Ghiringhelli F: FOXP3 expression in cancer cells and anthracyclines efficacy in patients with primary breast cancer treated with adjuvant chemotherapy in the phase III UNICANCER-PACS 01 trial. Ann Oncol 2012;23:2552-2561.

39 Xue J, MX. L, XL. Y, Wang J, Zhang TT, LS. S: Foxp3 gene expression in gastric cancer cells. J Diag Conc Prac 2009;8:160-164.

40 Li YM, Pan Y, Wei Y, Cheng X, Zhou BP, Tan M, Zhou X, Xia W, Hortobagyi GN, Yu D, Hung MC: Upregulation of CXCR4 is essential for HER2-mediated tumor metastasis. Cancer Cell 2004;6:459-469.

41 Douglass S, Meeson AP, Overbeck-Zubrzycka D, Brain JG, Bennett MR, Lamb CA, Lennard TW, Browell D, Ali S, Kirby JA: Breast cancer metastasis: demonstration that FOXP3 regulates CXCR4 expression and the response to CXCL12. J Pathol 2014;234:74-85.

42 Zhou Q Zheng X, Chen L, Xu B, Yang X, Jiang J, Wu C: Smad2/3/4 Pathway Contributes to TGF-beta-Induced MiRNA-181b Expression to Promote Gastric Cancer Metastasis by Targeting Timp3. Cell Physiol Biochem 2016;39:453-466.

43 Liu JF, Nie XC, Shao YC, Su WH, Ma HY, Xu XY: Bleomycin Suppresses the Proliferation and the Mobility of Human Gastric Cancer Cells Through the Smad Signaling Pathway. Cell Physiol Biochem 2016;40:14011409.

44 Samon JB, Champhekar A, Minter LM, Telfer JC, Miele L, Fauq A, Das P, Golde TE, Osborne BA: Notch1 and TGFbeta1 cooperatively regulate Foxp3 expression and the maintenance of peripheral regulatory $\mathrm{T}$ cells. Blood 2008;112:1813-1821.

45 Jarnicki AG, Lysaght J, Todryk S, Mills KH: Suppression of antitumor immunity by IL-10 and TGF-betaproducing T cells infiltrating the growing tumor: influence of tumor environment on the induction of CD4+ and CD8+ regulatory T cells. J Immunol 2006;177:896-904. 